\title{
Flora Fanerogâmica do Parque Estadual da Serra do Brigadeiro, Minas Gerais, Brasil: Begoniaceae ${ }^{1}$
}

Phanerogamic Flora of the Serra do Brigadeiro State Park, Minas Gerais, Brazil: Begoniaceae

\author{
Carolina Delfini ${ }^{2,4} \&$ Vinicius Castro Souza ${ }^{3}$
}

\begin{abstract}
Resumo
O presente estudo refere-se ao levantamento das espécies de Begoniaceae ocorrentes no Parque Estadual da Serra do Brigadeiro (PESB), Minas Gerais, Brasil. No Parque foram encontradas 10 espécies da família, todas elas pertencentes a Begonia: B. altamiroi, B. angulata, B. convolvulacea, B. cucullata, B. fischeri, B. fruticosa, $B$. hugelii, B. integerrima, $B$. luxurians e $B$. riedelii, as quais podem ser diferenciadas principalmente pelo hábito, pelo aspecto geral do limbo e pelo indumento. Do total, oito espécies são exclusivas do Brasil e sete endêmicas da Mata Atlântica. Este estudo baseou-se em levantamento bibliográfico, consulta aos principais herbários do país e observações de campo. Constam também descrições, ilustrações e comentários.
\end{abstract}

Palavras-chave: Begonia, Mata Atlântica, taxonomia.

\begin{abstract}
A taxonomic survey for Begoniaceae occurring in the Serra do Brigadeiro State Park (PESB), Minas Gerais, Brazil is presented in this study. Ten species of Begoniaceae were found at the park, all of them belonging to Begonia: B. altamiroi, B. angulata, B. convolvulacea, B. cucullata, B. fischeri, B. fruticosa, B. hugelii, B. integerrima, $B$. luxurians and $B$. riedelii, mainly distinguished by features of habit, by the general aspect of leaf blades, and indument. Of the total, eight species are endemic to Brazil, whilst seven are endemic from the Atlantic Forest. The study was based on bibliographic review, consults to the main Brazilian herbaria, and field observation. Descriptions, illustrations, and comments are also presented for each species.
\end{abstract}

Key words: Begonia, Atlantic Forest, taxonomy.

\section{Introdução}

Begoniaceae é composta por dois gêneros: Hillebrandia Oliv., monotípico e exclusivo do arquipélago do Havaí e Begonia L. com aproximadamente 1500 espécies de ervas e subarbustos amplamente distribuídos pelos trópicos e subtrópicos (Neale et al. 2006; Wilde 2011). Nas Américas encontram-se cerca de 530 espécies; na África, incluindo Madagascar, aproximadamente 150 espécies e na Ásia cerca de 520 espécies (Doorenbos et al. 1998).

A família está inserida em Cucurbitales e é caracterizada pelos caules suculentos, estípulas amplas, lâminas foliares geralmente assimétricas, flores unissexuais e pelas cápsulas loculicidas trialadas (Clement et al. 2004). A maioria das espécies de Begonia apresenta potencial ornamental com folhas vistosas, frequentemente variegadas e diversas espécies e híbridos são cultivados no Brasil com essa finalidade (Brade 1957; Souza \& Lorenzi 2012), como por exemplo, Begonia aconitifolia A. DC., Begonia bowerae Ziesenh., Begonia x elatior Hort. ex Steud., Begonia x sementacea Hort., entre outros.

As espécies nativas do Brasil (aproximadamente 240) estão concentradas na Mata Atlântica, especialmente na Serra do Mar, ocorrendo desde o sul da Bahia até o Rio Grande

\footnotetext{
${ }^{1}$ Parte da dissertação de Mestrado da primeira autora.

${ }^{2}$ Universidade Estadual de Campinas, Inst. Biologia, Depto. Biologia Vegetal, C.P. 6109, 13083-970, Campinas, SP, Brasil.

${ }^{3}$ USP/Escola Superior de Agricultura "Luiz de Queiroz", Depto. Ciências Biológicas, Av. Pádua Dias 11, 13418-900, Piracicaba, SP, Brasil.

${ }^{4}$ Autora para correspondência: cdelfini@gmail.com
} 
do Sul, sendo raras as espécies amazônicas (Duarte 1961; Smith et al. 1986; BFG 2015). Essas espécies crescem particularmente em formações cujo índice higrométrico é muito elevado e as precipitações sem grandes intervalos entre uma e outra. Dessa forma, a maioria das espécies de Begonia é encontrada em interiores de florestas, margens de cursos d'água, grotas úmidas e sombreadas e entre rochas onde corre água com frequência (Duarte 1961).

A região Sudeste - com cerca de 160 espécies - representa a área mais rica tanto em endemismo quanto em número de espécies (Delfini 2009; Kollmann 2012; Mamede et al. 2012; BFG 2015). Em Minas Gerais, as cabeceiras do Vale do Rio Doce, a Cadeia do Espinhaço, a Zona da Mata e a Serra da Mantiqueira ao longo do Rio Paraibuna, são locais que apresentam condições de clima favorável para o desenvolvimento de Begoniaceae, no entanto, admite-se que muitas espécies desapareceram com os desmatamentos destinados à agricultura (Duarte 1961). Ainda assim, nesse estado foram registradas 31 espécies de Begoniaceae, das quais quatro são exclusivas (Delfini 2009). Na Serra do Cipó foram registradas quatro espécies (Jacques 1999) e Begonia grisea A. DC. para a Serra de Grão Mogol (Jacques 2003).

O Parque Estadual da Serra do Brigadeiro (PESB) está localizado no extremo norte da Zona da Mata mineira, a cerca de $290 \mathrm{~km}$ de Belo Horizonte, entre as coordenadas $20^{\circ} 33^{\prime}-21^{\circ} 00^{\prime} \mathrm{S}$ e 42 $40^{\prime}-40^{\circ} 20^{\prime}$ W. O Parque ocupa uma área de 14984 ha., abrangendo os municípios de Araponga, Divino, Ervália, Fervedouro, Miradouro, Muriaé, Pedra Bonita e Sericita, tendo como ponto culminante o Pico do Soares com 1985 metros de altitude (IEF 2016).

As principais formações vegetais do Parque são compostas por fragmentos de Mata Atlântica (predominantemente Floresta Ombrófila Densa) e por campos de altitude. De acordo com o Atlas de Conservação da Biodiversidade de Minas Gerais, o Parque Estadual da Serra do Brigadeiro possui um dos últimos remanescentes de Mata Atlântica de Minas Gerais (IEF 2016) e, portanto, constitui uma área de extrema importância biológica para a conservação.

O presente estudo tem como objetivo catalogar e descrever a diversidade das espécies de Begoniaceae ocorrentes no PESB. Em adição, este trabalho objetiva contribuir para o conhecimento da flora de Minas Gerais, assim como da Mata Atlântica.

\section{Material e Métodos}

O presente estudo foi baseado em levantamento bibliográfico, observações de campo e em espécimes depositados nos seguintes herbários: BHCB, ESA, GFJP, PAMG, RB, SP, SPF e VIC (acrônimos de acordo com Thiers, continuamente atualizado).

A descrição do gênero foi baseada nos espécimes analisados e também nos tratamentos taxonômicos prévios do grupo (Jacques 2002; Delfini 2009; Kollmann 2012; Mamede et al. 2012). As descrições das espécies foram baseadas exclusivamente nos materiais analisados. A terminologia morfológica adotada no presente estudo está de acordo com Font Quer (1953), Radford et al. (1974), Smith et al. (1986), Weberling (1992) para as inflorescências, Harris \& Harris (2001) para o indumento e Golding \& Wasshausen (2002).

\section{Resultados e Discussão}

No PESB foram registradas 10 espécies de Begonia: B.altamiroi, B. angulata, $B$. convolvulacea, B. cucullata, B. fischeri, $B$. fruticosa, B. hugelii, B. integerrima, B. luxurians e $B$. riedelii, as quais podem ser diferenciadas principalmente pelo hábito, pelo aspecto geral do limbo e pelo indumento. Do total, oito espécies possuem distribuição exclusiva no Brasil, sendo $B$. angulata, B. convolvulacea, B. fruticosa, B. hugelii, $B$. integerrima, $B$. luxurians e $B$. riedelii endêmicas da Mata Atlântica.

No PESB as espécies de Begonia habitam locais úmidos e sombreados, tais como interiores de florestas, entre fendas de rochas, expostas em pleno sol (menos frequente) ou em locais parcialmente iluminados de florestas, afloramentos rochosos e campos de altitude, entre 860 e 1400 metros. De forma geral, os interiores das trilhas de florestas, como por exemplo, a Trilha do Mucuri, Trilha do Carvão, Trilha do Pico do Gama, e aquelas localizadas próximas da sede da Fazenda Neblina, são as áreas com maior concentração de espécies.

\section{Tratamento taxonômico}

Begonia L., Sp. pl.: 1056. 1753. Tipo: Begonia obliqua L., Sp. pl., 2: 1056. 1753.

Ervas ou subarbustos, raramente arbustos. Caules geralmente carnosos, com estípulas. Lâminas alternas, raramente opostas ou verticiladas, simples, raramente compostas, inteiras a profundamente partidas, frequentemente 
lobadas, geralmente assimétricas e palminérveas. Inflorescências cimosas, axilares, unissexuais ou bissexuais, flores diclinas, pediceladas, prefloração imbricada, brácteas 1 par, bractéolas presentes e em número variável, tépalas petalóides livres ou parcialmente unidas, brancas, róseas ou vermelhas. Flores estaminadas: tépalas 2 ou 4 , neste caso dispostas em dois verticilos (dois maiores e dois menores). Estames 4 a numerosos com filetes livres ou às vezes unidos na base, anteras rimosas ou poricidas. Flores pistiladas: tépalas 2-6, mais frequentemente 5. Gineceu 2-5-carpelar, 2-5-locular (mais frequentemente 3-locular), ovário ínfero, estigma com ramos cilíndricos e espiralados ou sinuosos, placentação axilar ou parietal, placenta inteira ou partida, óvulos numerosos e bitegumentados, número de ramos do estigma igual ao número de carpelos, bífidos no ápice. Cápsula loculicida trialada, deiscente por fendas ou poros, normalmente com alas desiguais, raramente baga. Sementes numerosas com testa ornamentada e pouco endosperma.

\section{Chave para identificação das espécies de Begonia ocorrentes no Parque Estadual da Serra do Brigadeiro:}

1. Lâminas palmatissectas

Begonia luxurians

1'. Lâminas inteiras ou lobadas

2. Nervação peninérvea.

Begonia fruticosa

2'. Nervação palminérvea 3

3. Plantas glabras

3'. Plantas com indumento

4. Lâminas cuculadas

Begonia cucullata

4'. Lâminas reniformes, ovais, cordiformes ou lobadas. 5

5. Lâminas 4-5(-6)-lobadas........................................................ Begonia riedelii

5'. Lâminas assimétricas ou levemente assimétricas.

6. Lâminas reniformes 4-6-dentadas, anteras rimosas

Begonia convolvulacea

6'. Lâminas ovais a cordiformes, anteras poricidas terminais

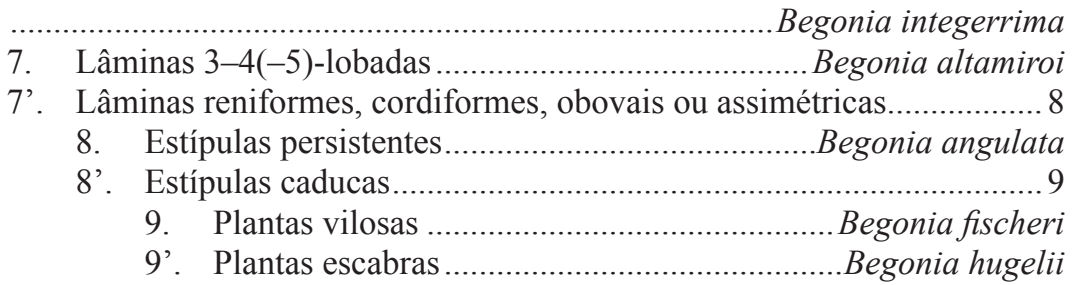

1. Begonia altamiroi Brade, Arq. Jard. Bot. Rio de Janeiro 8: 230, pl. 4. 1948.

Fig. 1a

Ervas robustas, 0,4-2 $\mathrm{m}$ alt. Caules eretos, subcarnosos, cilíndricos, estriados, ramificados, verdes a marrons, laxamente tomentosos, tricomas simples. Estípulas 0,9-2 ×0,3-0,5 cm, lanceoladas, ápice mucronulado, base truncada, margem inteira a levemente ondulada, membranáceas, caducas, apressas, carenadas, carenas tomentosas; pecíolos 4,5-12,5 cm comp., cilíndricos, estriados, tomentosos. Lâminas (9-)11-20 × (4-)6-9 $\mathrm{cm}$, assimétricas, 3-4(-5)-lobadas, basifixas, papiráceas, lobos lanceolados com ápices acuminados a agudos, base cordada, margem serrilhada, tomentosas em ambas as faces, sendo o indumento mais concentrado sobre as nervuras, face adaxial verde, abaxial verde a avermelhada, venação palminérvea, nervuras 3-4, raramente 5 . Cimeiras multifloras, pedúnculos $(4,5-) 5,5-19$ cm comp., glabrescentes; brácteas ca. 3,0 $\times 1$ $\mathrm{mm}$ larg., triangulares, caducas, glabrescentes; bractéolas 1-4 pares. Flores estaminadas tépalas 4 , as externas $8 \times 6-7 \mathrm{~mm}$, obovais, esparsamente tomentosas, tricomas esparsos, as internas ca. $6 \times 2$ $\mathrm{mm}$, elípticas, glabras, alvas a róseas; bractéolas ca. $3 \times 1 \mathrm{~mm}$, lanceoladas, caducas, carenadas, carenas tomentosas; estames 20-30, ca. $3 \mathrm{~mm}$ comp., filetes livres; anteras 1-2 mm comp., rimosas, oblongas. Flores pistiladas tépalas5, subiguais, uma delas ligeiramente desigual no tamanho e forma, 4,7-7 × 3,5-5,5 $\mathrm{mm}$, elípticas, laxamente tomentosas, brancas a róseas; bractéolas ca. $3 \times 1$ $\mathrm{mm}$, lanceoladas, caducas, laxamente tomentosas; estilete 3-4 mm comp.; ramos do estigma ca. 2 


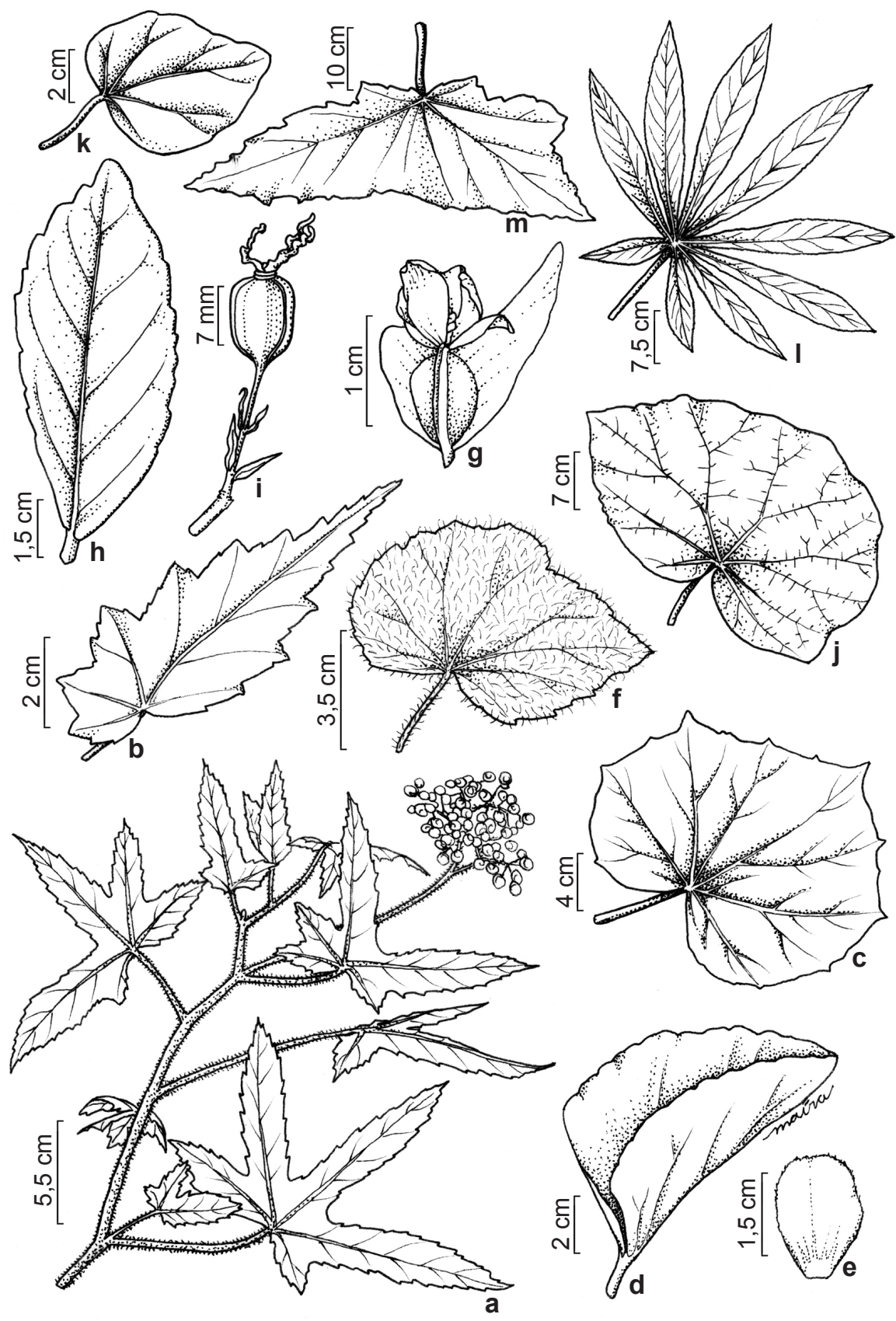

Figura 1 -a. B. altamiroi-hábito; b. B. angulata - detalhe da folha; c. B. convolvulacea - detalhe da folha; d-e. B. cucullata - d. detalhe da folha; e. detalhe da estípula; f-g. $B$. fischeri - f. detalhe da folha; g. detalhe do fruto jovem; h-i. $B$. fruticosa-h. detalhe da folha; i. detalhe do fruto; j. B. hugelii - detalhe da folha; k. B. integerrima - detalhe da folha; 1. B. luxurians - detalhe da folha; m. B. riedelii - detalhe da folha. [a: L.S. Leoni 2563 (SP); b: L.S. Leoni 1746 (SP); c: C. Delfini 37 \& J. Paula-Souza (ESA); d-e: C. Delfini 47 \& J. Paula-Souza (ESA); f-g: C. Delfini 46 \& J. Paula-Souza (ESA); h-i: C. Delfini 44 \& J. Paula-Souza (ESA); j: L.S. Leoni 2569 (SP); k: C. Delfini 38 \& J. Paula-Souza (ESA); 1: C. Delfini 45 \& J. Paula-Souza (ESA); m: C. Delfini 39 \& J. Paula-Souza (ESA)].

Figure 1 -a. B. altamiroi-habit; b. B. angulata-detail of leaf; c. B. convolvulacea-detail of leaf; d-e. B. cucullata-d. detail of leaf; e. detail of stipule; f-g. B. fischeri-f. detail of leaf; g. detail of young fruit; h-i. B. fruticosa-h. detail of leaf; i. detail of fruit; j. B. hugelii-detail of leaf; k. B. integerrima - detail of leaf; 1. B. luxurians - detail of leaf; m. B. riedelii - detail of leaf. [a: L.S. Leoni 2563 (SP); b: L.S. Leoni 1746 (SP); c: C. Delfini 37 \& J. Paula-Souza (ESA); d-e: C. Delfini 47 \& J. Paula-Souza (ESA); f-g: C. Delfini 46 \& J. Paula-Souza (ESA); h-i: C. Delfini 44 \& J. Paula-Souza (ESA); j: L.S. Leoni 2569 (SP); k: C. Delfini 38 \& J. Paula-Souza (ESA); 1: C. Delfini 45 \& J. Paula-Souza (ESA); m: C. Delfini 39 \& J. Paula-Souza (ESA)]. 
mm comp., hipanto glabrescente. Cápsulas 5-8 $\times$ 0,8-1,3 cm larg., placentas inteiras; alas diferentes entre si, sendo a ala maior levemente ascendente com ápice arredondado. Sementes oblongas.

Material examinado: Araponga, Serra da Araponga Fazenda Neblina. Cresce no interior da floresta próximo

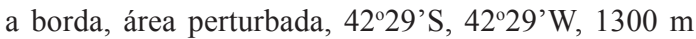
alt., 25.V.1994, fl. e fr., L.S. Leoni 2563 (GFJP, SP); Fervedouro, Parque Estadual da Serra do Brigadeiro. Mata Atlântica em diversos graus de perturbação, 2042'58'S, 42²9'02'W, 1400 m alt.,10.VII.1999, fl. e fr., J.A. Lombardi 3098 (BHCB).

Material adicional examinado: BRASIL. ESPÍRITO SANTO: Itaguassu. Santa Maria, 23.V.1943, fl. e fr., A.C. Brade 18400 et al. (MBML; SP; RB).

Begonia altamiroi é uma espécie exclusiva do Brasil, com registros de ocorrências apenas para os estados de Minas Gerais e Espírito Santo (BFG 2015). No PESB, B. altamiroi cresce em locais parcialmente iluminados no interior de florestas de encosta, tais como as trilhas próximas à sede da Fazenda Neblina e também em áreas perturbadas.

Begonia altamiroi possui as lâminas 3-4(-5)-lobadas com lobos lanceolados como características marcantes (Fig. 1a). Esta espécie assemelha-se no aspecto geral a $B$. rufa, a qual possui distribuição mais ampla, no entanto difere desta última espécie pela forma dos lobos [lanceolados em B. altamiroi vs. arredondados (pelo menos um) em B. rufa] e estípulas (lanceoladas em $B$. altamiroi vs. oval a triangular em $B$. rufa). Devido a essa semelhança, Kollmann (2012) tratou B. altamiroi como sinônimo de B. rufa. No entanto, além dos aspectos mencionados acima, esses táxons podem ser reconhecidos como entidades distintas com base nas seguintes características: inflorescências compostas por menos flores (50-80), flores estaminadas com tépalas externas tomentosas e tépalas internas glabras em $B$. altamiroi, contrapondo com inflorescências mais robustas (100-200 flores), flores estaminadas com tépalas externas tomentosas e carenadas e tépalas internas tomentosas em B. rufa.

2. Begonia angulata Vell., Fl. flum. icon. 10: pl. 52, (1827) 1831.

Fig. $1 \mathrm{~b}$

Ervas 0,5-1,5 $\mathrm{m}$ alt. Caules eretos a escandentes, suculentos, cilíndricos, pouco ramificados, verdes, glabrescentes, tricomas simples. Estípulas 0,5-1,5 × 0,3-0,9 cm, lanceoladas a estreitamente elípticas, ápice mucronulado, base truncada, margem inteira, membranáceas, persistentes, apressas, com uma crista de tricomas no dorso; pecíolos $0,8-3,5(-4,7)$ cm comp., cilíndricos, com tricomas esparsos. Lâminas (3-)4,5-11 × 1-3,5(-4,5) cm, inteiras, basifixas, membranáceas a papiráceas, ovallanceoladas, assimétricas, ápice acuminado, base subcordada a cordada, margem dentado-serrilhada, glabrescentes, tricomas geralmente distribuídos mais densamente na face abaxial, face adaxial verde, abaxial verde a avermelhada, venação palminérvea, nervuras 4-6. Cimeiras multifloras; pedúnculos (3,5-)4,5-15 cm comp., glabrescentes; brácteas $1-1,3 \times 5 \mathrm{~mm}$, triangulares, caducas, glabras; bractéolas 1-2 pares. Flores estaminadas tépalas 4 , as externas $0,5-1 \times 0,3-0,8 \mathrm{~cm}$, ovais a largamente obovais, glabrescentes, as internas 0,5 $1 \times 0,1-0,4 \mathrm{~cm}$, elípticas a estreitamente elípticas, glabras, alvas a levemente róseas; bractéolas $2-4 \times$ $1 \mathrm{~mm}$, lanceoladas, caducas, glabras; estames 15 25, 3-4 mm comp., filetes livres; anteras ca. $2 \mathrm{~mm}$ comp., rimosas, oblongas. Flores pistiladas tépalas 5 , uma delas ligeiramente desigual no tamanho e forma, $0,5-0,7 \times 0,2-0,7 \mathrm{~cm}$, ovais a obovais, glabras, alvas a levemente róseas; bractéolas $5 \times$ 1-2 mm, lanceoladas, caducas, glabras; estilete 2-3 mm comp.; ramos do estigma 1-2 mm comp., hipanto glabro. Cápsulas 0,8-1,4 × 1,4-1,6 cm, placentas inteiras; alas diferentes entre si, sendo a maior levemente ascendente com ápice obtuso a agudo. Sementes elípticas.

Material examinado: Araponga, Fazenda Neblina. Interior da floresta de encosta, em área perturbada, em direção ao lajeado ao lado da trilha, $20^{\circ} 46^{\prime} \mathrm{S}, 42^{\circ} 02^{\prime} \mathrm{W}$, $1300 \mathrm{~m}$ alt., 1.II.1992, fl. e fr., L.S. Leoni 1746 (GFJP, $\mathrm{SP})$.

Begonia angulata é uma espécie com distribuição exclusiva no Brasil, ocorrendo nos estados de Santa Catarina, Paraná e na região sudeste (BFG 2015). No PESB, esta espécie habita interiores de floresta de encosta e áreas perturbadas.

Begonia angulata é caracterizada por apresentar lâminas oval-lanceoladas com margem dentado-serrilhada (Fig. 1b). O indumento esparso dos pecíolos e as estípulas lanceoladas são características acessórias para o reconhecimento desta espécie.

Baseando-se em características do hábito, lâminas e indumento, Brade (1945) reconheceu três variedades para $B$. angulata: $B$. angulata var. angulata, B. angulata var. campos-portoi Brade e $B$. angulata var. serrana Brade. De acordo com a obra original, B. angulata var. campos-porto $i$ difere de B. angulata var. angulata pelo porte mais robusto, pelas folhas com dimensões menores e pelo indumento piloso nos caules e pecíolos. Já $B$. angulata var. serrana caracteriza-se principalmente 
Tabela 1 - Características diagnósticas de B. convolvulacea, B. fruticosa e B. integerrima.

Table 1 - Diagnostic features of $B$. convolvulacea, B. fruticosa and B. integerrima.

\begin{tabular}{llll}
\hline & B. convolvulacea & B. fruticosa & B. integerrima \\
\hline Forma das lâminas & reniformes & elípticas a ovais & ovais a cordiformes \\
Anteras & rimosas & rimosas, introrsas & poricidas \\
Cápsulas & alas dorsais desenvolvidas e & alas pouco desenvolvidas ou & alas dorsais desenvolvidas e \\
& diferentes entre si & rudimentares & diferentes entre si \\
\hline
\end{tabular}

pelo indumento hirsuto esparso dos pecíolos, pelo hábito mais delgado e pelas inflorescências mais densas. No PESB há registros de coleta apenas de B. angulata var. angulata.

3. Begonia convolvulacea (Klotzsch) A. DC. in Mart., Fl. bras. 4(1): 367. $1861 . \quad$ Fig. 1c

Ervas trepadeiras, atingindo até $2 \mathrm{~m}$ do solo. Caules escandentes, suculentos, estriados, simples, verdes, glabros. Estípulas 1,5-2 $\times$ $0,5-0,8 \mathrm{~cm}$, triangulares, ápice mucronulado, base truncada, margem inteira, membranáceas, tardiamente caducas, apressas, glabras; pecíolos 2,7-8,5(-11,5) cm comp., estriados, glabros. Lâminas 4,5-11,5 × 7,5-16 cm, inteiras, basifixas, papiráceas, reniformes, 4-6-dentadas, assimétricas, ápices agudos, base subcordada a cordada, margem dentado-serreada, glabras e verdes em ambas as faces, venação palminérvea, nervuras 4-6. Cimeiras multifloras; pedúnculos 7,5-12 cm comp., glabros; brácteas 3-7 × 2-3 $\mathrm{cm}$, lanceoladas, caducas, glabras; bractéolas 1-2 pares. Flores estaminadas tépalas 4, as externas ca. $5 \times 3-4 \mathrm{~mm}$, obovais, glabras, as internas 5 $\times 3-5 \mathrm{~mm}$, largamente obovais, glabras, alvas a esverdeadas; bractéolas $0,1-0,2 \times 1 \mathrm{~mm}$, lanceoladas, persistentes, glabras; estames 20-30, 4-5 mm comp., filetes livres; anteras ca. $2,5 \mathrm{~mm}$ comp., rimosas, oblongas. Flores pistiladas tépalas 5 , uma delas ligeiramente desigual no tamanho, 5 $\times$ 3-4 mm, obovais, glabras, alvas a esverdeadas; bractéolas $3 \times 1 \mathrm{~mm}$, lanceoladas, persistentes, glabras; estilete $4-5 \mathrm{~mm}$ comp.; ramos do estigma 3-4 mm comp., ramos cilíndricos e espiralados, hipanto glabro. Cápsulas $0,5-1 \times$ $1-1,5 \mathrm{~cm}$, placentas inteiras; alas diferentes entre si, sendo a maior levemente ascendente com ápice arredondado. Sementes elípticas.

Material examinado: Araponga, Parque Estadual da Serra do Brigadeiro, trilha do Mucuri. Interior de mata, 2040'S, 42³1'60”'W, 1300-1325 m.s.m., 23.III.2008, fl. e fr., C. Delfini \& J. Paula-Souza 37 (ESA, SPF);
Fazenda Neblina, Parque Estadual. 1125 m alt.,22 IX 2000, fl., L.S. Leoni 4496 (GFJP, SP); Serra da Gama, a mais ou menos $1 \mathrm{~km}$ antes da Fazenda da Neblina; estrada para Bom Jesus da Madeira, 8.X.1986, fl. e fr., M.F. Vieira 453 et al. (VIC).

Begonia convolvulacea é uma espécie exclusiva do Brasil, ocorrendo desde o Paraná até o Ceará (BFG 2015). No PESB, B. convolvulacea é encontrada em locais úmidos e sombreados.

Begonia convolvulacea apresenta as lâminas reniformes, 4-6-dentadas com ápices agudos (Fig. 1c), características únicas entre as espécies de Begonia do PESB. B. convolvulacea compartilha o hábito escandente com $B$. fruticosa e com $B$. integerrima, podendo ser prontamente distinta desta última espécie pelas características apresentadas na Tabela 1.

4. Begonia cucullata Willd., Sp. pl. 4(1): 414. 1805.

Fig. 1d-e

Ervas 0,3-1 m alt. Caules eretos, suculentos, cilíndricos ou estriados, simples ou pouco ramificados, verdes a avermelhados, glabros, Estípulas 1,2-2,5(-3) × 0,5-1,5 cm, oblongas a ovais, ápice arredondado, base truncada, margem dentada, ciliada a fimbriada, membranáceas, persistentes, apressas, glabras; pecíolos $(0,5-)$ 1,5-3,5 cm comp., cilíndricos, estriados, glabros. Lâminas 5,0-9,5 × 3,3-7,5 cm, inteiras, basifixas, membranáceas, cuculadas, assimétricas, ápice obtuso a arredondado, base subaguda, margem crenada a serreada, ciliada, glabras, verdes em ambas as faces, venação palminérvea, nervuras 5-8. Cimeiras paucifloras; pedúnculos 4,5-5,5 cm comp., glabros; brácteas $0,5-0,6 \times 0,2-0,3$ $\mathrm{cm}$, ovais a elípticas, tardiamente caducas, glabras; bractéolas 1-2 pares. Flores estaminadas tépalas 4 , as externas $0,5-1 \times 0,6-1,1 \mathrm{~cm}$, orbiculares, glabras, as internas $5-7 \times 2-3 \mathrm{~mm}$ larg., elípticas, glabras, alvas a róseas; bractéolas $3 \times 1 \mathrm{~mm}$, espatuladas, persistentes, glabras; estames 40-70, 5-6 mm comp., filetes livres; 
anteras ca. $3 \mathrm{~mm}$ comp., rimosas, oblongas. Flores pistiladas tépalas 5, subiguais, 0,7-1,3 $\times$ 0,4-0,8 cm, ovais a largamente ovais, glabras, alvas a róseas; bractéolas $5 \times 2-3 \mathrm{~mm}$, ovais a obovais, persistentes, glabras; estilete 4-5 mm comp.; ramos do estigma ca. $3 \mathrm{~mm}$ comp., hipanto glabro. Cápsulas 1,5-2 × 1,5-2,3 cm, placentas partidas; alas diferentes entre si, sendo a ala maior ascendente com ápice agudo. Sementes elípticas a fusiformes.

Material examinado: Araponga, Parque Estadual da Serra do Brigadeiro. Estrada para a entrada do Parque, beira da estrada, 2040'S, 42³1'60'W, 1125 m.s.m., 23.III.2008, fl. e fr., C. Delfini \& J. Paula-Souza 47 (ESA, SPF); Serra da Araponga - Fazenda Neblina. Cresce na trilha "Ranunculaceae" em área perturbada, 26.V.1994, fl. e fr., L.S. Leoni 2567 (GFJP, SP).

Begonia cucullata é uma espécie de ampla distribuição na América do Sul, ocorrendo desde a Venezuela até a Argentina (Jacques 2002). No Brasil ocorre nas regiões Sul, Sudeste e CentroOeste e na Bahia (BFG 2015). No PESB, $B$. cucullata pode ser encontrada em ambientes diversificados, tanto expostas em pleno sol ou parcialmente iluminados quanto em locais úmidos e sombreados e também entre fendas de rochas.

Begonia cucullata é uma espécie polimórfica, no entanto, pode ser prontamente reconhecida, mesmo em estado vegetativo, pela forma cuculada das lâminas e pelas estípulas espatuladas (Fig. 1d-e).

Com base em características das folhas e das estípulas, Golding (1982), Smith et al. (1986) e Golding \& Wasshausen (2002) reconheceram três variedades para $B$. cucullata: B. cucullata var. cucullata, B. cucullata var. arenosicola (C. DC.) L.B. Sm. \& B.G. Schub. e B. cucullata var. spatulata (Lodd.) Golding. De acordo com esses autores, a primeira variedade caracteriza-se por apresentar lâminas oblongas a cordiformes e estípulas oblongas, a segunda possui lâminas largamente elípticas e estípulas elípticas, enquanto a terceira apresenta folhas largamente ovais e estípulas oblongas. No PESB há registros de ocorrência apenas de $B$. cucullata var. cucullata.

5. Begonia fischeri Schrank, P1. rar. hort. Acad. monac., 2(6): pl. 59.1819 (1820). $\quad$ Fig. 1f-g

Ervas delicadas, 0,3-1 $\mathrm{m}$ alt. Caules eretos, suculentos, cilíndricos a estriados, pouco ramificados, verdes a avermelhados, vilosos, tricomas simples. Estípulas 0,5-1 × 0,3-0,5 $\mathrm{cm}$, lanceoladas, ápice mucronulado, raramente obtuso, base truncada, margem fimbriada, membranáceas, caducas, apressas, vilosas; pecíolos 1-3 cm comp., estriados, vilosos. Lâminas 2,5-6,5 × 1,5-4 cm, inteiras, basifixas, papiráceas, cordiformes a largamente obovais, assimétricas, ápice agudo, base cordada, margem irregularmente serreada a crenada, ciliada, vilosas, face adaxial verde, abaxial verde a rosada, venação palminérvea, nervuras 5-7. Cimeiras paucifloras; pedúnculos 2,5-4 cm comp.; brácteas ca. $5 \times 3$ mm, ovais, persistentes, vilosas; bractéolas 1-3 pares. Flores pistiladas tépalas 4 , as externas 6-8 $\times 5-7 \mathrm{~cm}$, largamente elípticas a orbiculares, glabras, as internas 5-7 × 2-3 cm, ovais, glabras, brancas a róseas; bractéolas 2-3× $1 \mathrm{~mm}$, obovais a espatuladas, persistentes, vilosas; estames 15-30, 3-4 mm comp., filetes livres; anteras ca. $2 \mathrm{~mm}$ comp., rimosas, oblongas. Flores pistiladas tépalas 5, semelhantes entre si, 3-5 × 3-4 mm, obovais, glabras, alvas a róseas; bractéolas $2-3 \times 2 \mathrm{~mm}$, ovais a espatuladas, persistentes, vilosas; estilete ca. 2,5 mm comp.; ramos do estigma ca. $1 \mathrm{~mm}$ comp.; hipanto glabro. Cápsulas 0,1-2,5 × 1,5-3,5 $\mathrm{cm}$, placentas partidas; alas diferentes entre si, sendo a ala maior bastante ascendente com ápice agudo. Sementes estreitamente elípticas.

Material examinado: Araponga, Parque Estadual da Serra do Brigadeiro. Estrada para a entrada do Parque. Local úmido, entre fendas de rochas, $20^{\circ} 40^{\prime} \mathrm{S}$, 42'31'60"W, 1125 m.s.m., 23.III.2008, fl. e fr., C. Delfini \& J. Paula-Souza 46 (ESA, SPF). Fervedouro, Zona da Mata, 2043'60"S, 42 ${ }^{\circ} 16$ '60"W, 860 m.s.m., 2.VIII.1992, fl. e fr., M. Brandão 19541 (PAMG).

Begonia fischeri é uma espécie de ampla distribuição, ocorrendo desde o México até a Argentina (Smith \& Smith 1971). No Brasil, B. fischeri distribui-se nas regiões Sul, Sudeste e Centro-Oeste e nos estados da Bahia, Pernambuco e Roraima (BFG 2015). No PESB esta espécie habita locais úmidos, parcialmente iluminados e entre fendas de rochas.

Begonia fischeri é uma espécie altamente polimórfica, mas pode ser prontamente reconhecida por apresentar lâminas cordiformes a largamente obovais (Fig. 1f), pelo indumento viloso dos caules e pecíolos e pelas cápsulas com a ala maior bastante ascendente e ápice agudo (Fig. 1g). A grande plasticidade morfológica de $B$. fischeri levou à descrição de diversas variedades (Irmscher 1953; Golding \& Wasshausen 2002), no entanto, como ainda não existe um consenso entre os autores para a definição dessas variedades, no presente estudo $B$. fischeri não foi tratada no nível intraespecífico. 
6. Begonia fruticosa A. DC. in Mart., Fl. bras. 4(1): 377. 1861

Fig. 1h-i

Subarbustos trepadores, atingindo 1,5-2 $\mathrm{m}$ alt. do solo. Caules escandentes, sublenhosos, cilíndricos, estriados, muito ramificados, marrons, glabros, pubérulos quando jovens. Estípulas $0,4-1 \times 0,1-0,3 \mathrm{~cm}$, triangulares a lanceoladas, ápice mucronulado, base truncada, margem inteira, membranáceas, persistentes, apressas, pubérulas; pecíolos $2-5 \mathrm{~mm}$ comp., cilíndricos, glabros. Lâminas 4,5-8 × 1,2-2,5 cm, inteiras, basifixas, papiráceas, elípticas a ovais, levemente assimétricas, ápice acuminado, base aguda a atenuada, margem serreada, esparsamente ciliada, glabras em ambas as faces, face adaxial verde, abaxial verde a avermelhada, peninérveas. Cimeiras geralmente paucifloras; pedúnculo 0,5-2 cm comp., glabros; brácteas 3-8 × 1-2 mm larg., triangulares a lanceoladas, persistentes, glabras; bractéolas 1-3 pares. Flores estaminadas tépalas 4, as externas $3-5 \times 2-3 \mathrm{~mm}$, ovais a obovais, glabras, as internas $2-5 \times 1-2 \mathrm{~mm}$, elípticas a obovais, glabras, alvas a esverdeadas; bractéolas ca. $2 \times 1$ $\mathrm{mm}$, lanceoladas, persistentes, glabras; estames 10-20, ca. $3 \mathrm{~mm}$ comp., filetes livres; anteras ca. $1 \mathrm{~mm}$ comp., introrsas, elípticas a oblongas. Flores pistiladas tépalas 5 , semelhantes no tamanho e forma, reflexas, $2-4 \times 1 \mathrm{~mm}$, lanceoladas, glabras, alvas a esverdeadas; bractéolas $2-3 \mathrm{~mm} \times 1 \mathrm{~mm}$, lanceoladas, persistentes, glabras; estilete 4-5 mm comp.; ramos do estigma ca. $3 \mathrm{~mm}$ comp., hipanto glabro. Cápsulas $0,5-1 \times 0,3-0,6 \mathrm{~cm}$, placentas inteiras; alas semelhantes entre si, pouco desenvolvidas ou rudimentares. Sementes fusiformes.

Material examinado: Araponga, Parque Estadual da Serra do Brigadeiro. Trilha do Mucuri. Interior de mata, 2040'S, 42 31'60'W, 1300-1325 m.s.m., 23.III.2008, fl. e fr., C. Delfini \& J. Paula-Souza 44 (ESA, SPF).

Begonia fruticosa possui distribuição restrita ao Brasil, ocorrendo desde a Bahia até o Rio Grande do Sul (BFG 2015). No PESB esta espécie foi coletada no interior de trilhas de florestas úmidas e sombreadas.

Begonia fruticosa é caracterizada pelo hábito subarbustivo escandente, pelas lâminas elípticas a ovais, peninérveas e pelos frutos com alas dorsais rudimentares (Fig. 1h-i). Esta espécie compartilha o hábito escandente com $B$. convolvulacea e $B$. integerrima, sendo prontamente separada destas espécies por características das lâminas, anteras e cápsulas (conforme discutido em $B$. convolvulacea).
7. Begonia hugelii (Klotzsch) A. DC. in Mart., Fl. bras. 4(1): 366.1861.

Fig. $1 \mathrm{j}$

Ervas robustas, até $2 \mathrm{~m}$ alt. Caules eretos, suculentos, estriados, simples, verdes, escabros, tricomas simples e escamas. Estípulas 1-1,5 $\times 0,5-1 \mathrm{~cm}$, triangulares, ápice mucronulado, base truncada, margem levemente ondulada, membranáceas, caducas, apressas, escabras; pecíolos (4-)4,5-13(-28) cm comp., estriados, escabros. Lâminas (19-)23-50 × 10,5-35 cm, inteiras, basifixas, papiráceas, reniformes, levemente lobadas, assimétricas, ápices agudos, base cordada, margem irregularmente ondulada a irregularmente crenada, glabrescentes, sendo o indumento mais concentrado na face abaxial e sobre as nervuras, verdes em ambas as faces, venação palminérvea, nervuras 5-7. Cimeiras multifloras; brácteas $0,7-1 \times 0,5-0,8 \mathrm{~cm}$, triangulares, caducas, escabras; bractéolas 1 par. Flores estaminadas tépalas 4 , as externas $4-5 \times 7 \mathrm{~mm}$, largamente elípticas a orbiculares, escabras e com glândulas salientes, as internas $4-5 \times 2-3 \mathrm{~mm}$, obovais, glabras, com glândulas salientes distribuídas na região central das tépalas, brancas; bractéolas $7 \times$ 3-5 mm, triangulares, caducas, escabras; estames 15-25, ca. $4 \mathrm{~mm}$ comp., filetes livres; anteras ca. $3 \mathrm{~mm}$ comp., rimosas, oblongas. Flores pistiladas tépalas 4-5, subiguais, sendo uma delas levemente desigual na forma, 3-4×2-3 mm, elípticas a ovais, glabras, com glândulas salientes, alvas; bractéolas ca. $7 \times 2-5 \mathrm{~mm}$, triangulares, caducas, escabras; estilete ca. $3 \mathrm{~mm}$ comp; ramos do estigma ca. 2 $\mathrm{mm}$ comp., hipanto escabro. Cápsulas $0,5-1 \times$ $0,9-1,7 \mathrm{~cm}$, placentas inteiras; alas diferentes entre si, sendo a maior levemente ascendente com ápice obtuso. Sementes oblongas.

Material examinado: Araponga, Fazenda Neblina. Floresta Estacional Semidecidual - Área um tanto perturbada, trilha da Ranunculaceae, 26.V.1995, fl., L.S. Leoni 2569 (GFJP, SP); Serra da Gama, estrada para Bom Jesus da Madeira, beira da estrada a mais ou menos 100 m da casa da sede da Fazenda Neblina, 9.X.1986, fr., M.F. Vieira et al. 476 (VIC); Fervedouro, Parque Estadual da Serra do Brigadeiro. Mata Atlântica em diversos graus de perturbação. 1400 m.s.m., 10.VII.1999, fl., J.A. Lombardi 3121 (BHCB).

Begonia hugelii possui distribuição restrita ao Brasil, ocorrendo na região Sudeste e no estado do Paraná (BFG 2015). No PESB, B. hugelii habita locais úmidos e parcialmente iluminados e com algum grau de perturbação.

Begonia hugelii possui o hábito robusto e o indumento escabro formado por tricomas e escamas como características marcantes. Esta espécie 
Tabela 2 - Características diagnósticas de B. convolvulacea e B. hugelii.

Table 2 - Diagnostic features of B. convolvulacea and B. hugelii.

\begin{tabular}{lll}
\hline & B. convolvulacea & B. hugellii \\
\hline Hábito & ervas escandentes & plantas robustas, terrestres \\
Indumento & glabro & escabro \\
Sementes & elípticas & oblongas \\
\hline
\end{tabular}

compartilha as lâminas reniformes (Fig. 1j) com B. convolvulacea, sendo prontamente distinta desta última espécie pelas características apresentadas na Tabela 2.

8. Begonia integerrima Spreng., Neue Entdeck. 2: 174. 1820.

Fig. 1k

Ervas hemiepífitas ou trepadeiras, atingindo até $7 \mathrm{~m}$ alt. do solo. Caules eretos a escandentes, suculentos, cilíndricos a estriados, ramificados, verdes, glabros. Estípulas $0,5-1,5 \times 0,3-0,7 \mathrm{~cm}$, ovais a triangulares, ápice mucronulado, base truncada, margem inteira, membranáceas, caducas a tardiamente caducas, apressas, glabras; pecíolos 1,5-5,5 cm comp., cilíndricos a estriados, glabros. Lâminas $(2,7-) 3,4-6 \times(1,5-) 2-4,5 \mathrm{~cm}$, inteiras basifixas, papiráceas, ovais a largamente ovais a cordiformes, simétricas a levemente assimétricas, ápice acuminado, base arredondada a cordada, margem inteira a levemente ondulada, glabras, face adaxial verde, abaxial verde a avermelhada, venação palminérvea, nervuras 4-6. Cimeiras paucifloras; brácteas $0,8-1,5 \times 0,3-0,7 \mathrm{~cm}$, ovais a lanceoladas, tardiamente caducas, glabras; bractéolas 1-2 pares. Flores estaminadas tépalas 4 , as externas $0,7-1,1$ $\times 0,5-1 \mathrm{~cm}$, ovais a largamente ovais, glabras, as internas $0,6-1,1 \times 0,2-0,7 \mathrm{~cm}$, elípticas, glabras, brancas, róseas ou vináceas; bractéolas $0,8-1,1 \times$ $0,5-0,8 \mathrm{~cm}$, ovais, tardiamente caducas, glabras; estames 10-20, ca. $4 \mathrm{~mm}$ comp., filetes unidos na base; anteras ca. $3 \mathrm{~mm}$ comp., poricidas terminais, elípticas. Flores pistiladas tépalas 5 , semelhantes no tamanho e forma, 1,0-1,5 × 0,3-1 cm, obovais, glabras, alvas a vináceas; bractéolas $0,8-1,1 \times$ $0,5-0,8 \mathrm{~cm}$, ovais, tardiamente caducas, glabras; estilete ca. $7 \mathrm{~mm}$ comp.; ramos do estigma ca. 3 mm comp., ramos cilíndricos e sinuosos, hipanto glabro. Cápsulas 0,5-1,5 × 0,7-1,7 cm, placentas partidas; alas diferentes entre si, sendo a maior levemente ascendente com ápice arredondado a obtuso. Sementes fusiformes.

Material examinado: Araponga, Parque Estadual da Serra do Brigadeiro. Trilha do Mucuri. Interior de mata,
2040'S, 42³1'60'W, 1300-1325 m.s.m., 23.III.2008, fl. e fr., C. Delfini \& J. Paula-Souza 38 (ESA, SPF); Serra da Araponga - Fazenda Neblina. Floresta Estacional Semidecidual. Cresce ao lado da estrada, próximo ao laboratório de campo, 9.VIII.1994, fl., L.S. Leoni 2633 (GFJP, SP).

Begonia integerrima possui distribuição restrita ao Brasil, ocorrendo exclusivamente nos estados da região Sudeste (BFG 2015). No PESB, $B$. integerrima habita locais úmidos e sombreados tal como interior de florestas, sendo menos frequente em bordas de trilhas.

As lâminas ovais a cordiformes levemente assimétricas (Fig. 1k), as anteras poricidas e as sementes fusiformes são características marcantes B. integerrima.

Segundo Jacques (2002), B. integerrima possivelmente cresce no solo, se apoia em troncos de árvores e posteriormente torna-se uma planta epífita formando um grande maciço.

9. Begonia luxurians Scheidw., Allg. Gartenzeitung, 16: 131. 1848. Fig. 11

Ervas robustas, até $3 \mathrm{~m}$ alt. Caules eretos, estriados, simples, verdes a avermelhados, glabrescentes, lanuginosas, indumento ferrugíneo formado por tricomas longos e finos (simples ou dicotômicos) e por tricomas estrelados esparsos. Estípulas 0,6-1,5 × 0,3-0,7 cm, triangulares, ápice mucronulado, base truncada, margem inteira a irregularmente ondulada, papiráceas, tardiamente caducas, apressas, lanuginosas; pecíolos (6,5-)7-11 cm comp., estriados, glabrescentes. Lâminas palmatissectas, segmentos (13-)16-32,6 × (2-)3$4,5 \mathrm{~cm}$, papiráceos, elípticos, simétricos a levemente assimétricos, ápices acuminados, raramente agudos, bases atenuadas, margem serreada a serrilhada, glabrescentes, sendo o indumento distribuído mais concentradamente na face abaxial das folhas, face adaxial verde, abaxial verde a avermelhada, 9-15 segmentos peninérveos. Cimeiras multifloras; pedúnculos $(8,5-) 15-40 \mathrm{~cm}$ comp., glabrescentes; brácteas ca. $1 \times 0,4 \mathrm{~cm}$, triangulares, caducas, 
lanosas; bractéolas 1-2 pares. Flores estaminadas tépalas 4 , as externas ca. $4 \times 3 \mathrm{~mm}$, largamente ovais, glabras ou com tricomas esparsos, as internas $4 \times 2-3 \mathrm{~mm}$, ovais, glabras, alvas a esverdeadas; bractéolas $6 \times 1-2 \mathrm{~mm}$, triangulares, caducas, lanuginosas; estames 15-25, ca. $3 \mathrm{~mm}$ comp., filetes livres; anteras ca. $1 \mathrm{~mm}$ comp., rimosas, oblongas. Flores pistiladas tépalas 5, semelhantes entre si, 3-4 × $2 \mathrm{~mm}$, elípticas, glabrescentes, alvas a esverdeadas; bractéolas $6 \times 1-2 \mathrm{~mm}$, triangulares, caducas, lanuginosas; estilete ca. $2 \mathrm{~mm}$ comp.; ramos do estigma ca. $1 \mathrm{~mm}$, hipanto glabrescente. Cápsulas ca. $5 \times 5-7 \mathrm{~mm}$, placentas inteiras; alas semelhantes entre, ápices arredondados. Sementes oblongas.

Material examinado: Araponga, Parque Estadual da Serra do Brigadeiro. Trilha do Mucuri. Interior de mata, 2040'S, 42³1'60'”W, 1300-1325 m.s.m., 23.III.2008, fl. e fr., C. Delfini \& J. Paula-Souza 45 (ESA, SPF); Fazenda Neblina - Floresta Estacional Semidecidual - Área um tanto perturbada, 19.V.1991, fl., L.S. Leoni 1572 (GFJP, SP); Serra do Brigadeiro, 4.IV.1992, fl., J.A.A. Meira Neto \& A.F. Silva 904 (VIC); Serra da Gama, estrada para Bom Jesus da Madeira, beira da estrada a mais ou menos 100 $m$ da casa da sede da Fazenda Neblina, 9.X.1986, fl., M.F. Vieira et al. 478 (VIC). Fervedouro, Parque Nacional da Serra do Brigadeiro. Mata Atlântica em diversos graus de perturbação, 2042'58'S, 42²9'02"W, 1400 m.s.m., 10.VII.1999, fl., J.A. Lombardi 3077 (BHCB).

Begonia luxurians é uma espécie exclusiva do Brasil, sendo encontrada nos estados da região Sudeste (Jacques 2015). No PESB, esta espécie foi coletada em locais úmidos e sombreados, bordas de florestas ou em locais com algum grau de perturbação, frequentemente próxima a cursos d'água.

Begonia luxurians possui as lâminas palmatissectas (Fig. 11) como característica única entre as espécies de Begonia do PESB. O porte robusto, as inflorescências multifloras e as cápsulas com alas dorsais desenvolvidas e semelhantes entre si são características complementares para a identificação desta espécie.

Baseando-se em características das lâminas, Brade (1944) reconheceu duas variedades para $B$ luxurians: B luxurians var. luxurians e $B$. luxurians var. sampaioana Brade. De acordo com a descrição original, $B$. luxurians var. sampaioana difere de B. luxurians var. luxurians por apresentar segmentos e peciólulos com maiores dimensões e margens levemente serrilhada (Brade 1944). Embora B. luxurians var. sampaioana distribuase exclusivamente no estado de Minas Gerais, no PESB há registros de coleta apenas de B. luxurians var. luxurians.
10. Begonia riedelii A. DC., Ann. Sci. Nat. Bot., IV, 11:137. 1859.Fig. $1 \mathrm{~m}$

Ervas robustas, até 2,5 m alt. Caules eretos, suculentos, estriados, simples a pouco ramificados, verdes a avermelhados, glabros. Estípulas 2-3,5 × $0,5-1,1 \mathrm{~cm}$, triangulares, ápice agudo, base truncada, margem inteira, membranáceas, persistentes, apressas, glabras; pecíolos (5-)5,5-16,5 cm comp., estriados, glabros, com colar de tricomas curtíssimos no ápice. Lâminas 17-34,5 × 7-13,5 cm, 4-5(-6)-lobadas, basifixas, papiráceas, elípticas, assimétricas, lobos com ápices agudos a acuminados, base cordada a profundamente cordada, margem irregularmente ondulada a denteada, glabras e verdes em ambas as faces, venação palminérvea, nervuras 3-5. Cimeiras multifloras; pedúnculo 15-36,2 cm comp., glabros; brácteas 1-1,5 × $0,3-0,5 \mathrm{~cm}$, triangulares a elípticas, caducas, glabras; bractéolas 1-3 pares. Flores estaminadas tépalas 4, as externas $0,5-1 \times 0,3-0,4 \mathrm{~cm}$, ovais a largamente ovais, glabras, as internas $0,5-1 \times 0,1-0,3 \mathrm{~cm}$, elípticas, glabras, alvas a róseas; bractéolas 3-4 $\times$ $2 \mathrm{~mm}$, triangulares, tardiamente caducas, glabras; estames 25-30, ca. $3 \mathrm{~mm}$ comp., filetes livres; anteras ca. $2 \mathrm{~mm}$ comp., rimosas, oblongas. Flores pistiladas tépalas 5 , uma delas ligeiramente desigual no tamanho e na forma, 5-8 $\times 2-3 \mathrm{~mm}$, ovais a largamente ovais, alvas a róseas; bractéolas 3-4 $\times 2 \mathrm{~mm}$, triangulares, glabras; estilete ca. $1 \mathrm{~mm}$; ramos do estigma ca. $1 \mathrm{~mm}$ comp., hipanto glabro. Cápsulas 0,7-1,3 × 1-2,3 cm, placentas inteiras; alas diferentes entre si, sendo a maior levemente ascendente com agudo a obtuso. Sementes oblongas. Material examinado: Araponga, Parque Estadual da Serra do Brigadeiro. Final da trilha do Mucuri. Área perturbada, $20^{\circ} 40^{\prime}$ 'S, 42 $31^{\prime} 60^{\prime} \mathrm{W}, 1300-1325$ m.s.m., 23.III.2008, fl. e fr., C. Delfini \& J. Paula-Souza 39 (ESA, SPF); Fervedouro, Parque Estadual da Serra do Brigadeiro. Mata Atlântica em diversos graus de perturbação, 1400 m.s.m., 10.VII.1999, fl. e fr., J.A. Lombardi 3119 (BHCB).

Begonia riedelii é uma espécie distribuída exclusivamente no Brasil, ocorrendo nos estados de Minas Gerais e Espírito Santo (Jacques 2015). No PESB B. riedelii é encontrada exposta em pleno sol ou em locais parcialmente iluminados, frequentemente em áreas com algum grau de perturbação.

Begonia riedelii é caracterizada por apresentar lâminas 4-5(-6)-lobadas (Fig. 1m) e pecíolos glabros com um colar curtíssimo de tricomas no ápice. As estípulas triangulares, persistentes e as cápsulas com a ala maior bastante ascendente e aguda são características complementares para o reconhecimento desta espécie. 


\section{Agradecimentos}

Agradecemos à Fundação de Amparo à Pesquisa do Estado de São Paulo, a concessão da bolsa de Mestrado à primeira autora (FAPESP 2006/58589-6). Aos curadores dos herbários consultados, por disponibilizarem suas coleções tanto durante as visitas pessoais quanto por meio de empréstimos. E a Maíra Mezzacappa, as ilustrações.

\section{Referências}

BFG. 2015. Growing knowledge: an overview of Seed Plant diversity in Brazil. Rodriguésia 66: 1085-1113.

Brade, A.C. 1944. Begoniaceae do herbário do Museu Nacional do Rio de Janeiro. Boletim do Museu Nacional do Rio de Janeiro, Botânica 1: 10.

Brade, A.C. 1945. Begônias novas do Brasil, III. Rodriguésia 18: 17-18.

Brade, A.C. 1957. Flora do Itatiaia. I. As "Begoniaceae" como fator fisionômico. Rodriguésia 20: 15-166.

Clement, W.L.; Tebbit, M.C.; Forrest, L.L.; Blair, J.E.; Brouillet, L.; Eriksson, T. \& Swensen, S.M. 2004. Phylogenetic position and biogeography of Hillebrandia sandwicensis (Begoniaceae): a rare Hawaiian relict. American Journal of Botany 91: 905-917.

Delfini, C. 2009. Flora de Minas Gerais: Begoniaceae. Dissertação de Mestrado. Instituto de Biociências. Universidade de São Paulo, São Paulo. 143p.

Doorenbos, J.; Sosef, M.S.M. \& Wilde, J.J.F.E. 1998. The sections of Begonia. 98-2. Wageningen Agricultural University Papers, Wageningen. 266p.

Duarte, A.P. 1961. Considerações acerca do comportamento e dispersão de algumas espécies de Begônias do Estado da Guanabara. Arquivos do Jardim Botânico do Rio de Janeiro 17: 56-105.

Font Quer, P. 1953. Diccionário de Botánica. Ed. Labor, Barcelona. 1244p.

Golding, J. 1982. Begonia nomenclature. Begonia cucullata Willd. and included species. Phytologia 50: 330-356.

Golding, J. \& Wasshausen, D.C. 2002. Begoniaceae. Part. I: annotated species list. Part. II: illustrated key. $2^{\text {nd }}$ ed. Smithsonian Institution, Washington. 289p.

Harris, J.G. \& Harris, M.W. 2001. Plant identification terminology: an illustrated glossary. $2^{\text {nd }}$ ed. Missouri Botanical Garden Library, Saint Louis. 206p.

IEF - Instituto Estadual de Florestas. 2016. Parque Estadual da Serra do Brigadeiro. Disponível em $<$ http://www. ief.mg.gov.br/component/content/197?task=view $>$. Acesso em 3 janeiro 2016.

Irmscher, E. 1953. Systematische studien über Begoniaceen des tropischen Sudamerickas besonders Brasiliens. Botanische Jahrbücher für Systematik 76: 1-102.
Jacques, E.L. 1999. Flora da Serra do Cipó, Minas Gerais: Begoniaceae. Boletim de Botânica da Universidade de São Paulo 18: 33-37.

Jacques, E.L. 2002. Estudos taxonômicos das espécies brasileiras do gênero Begonia L. (Begoniaceae) com placenta partida. Tese de Doutorado. Instituto de Biociências. Universidade de São Paulo, São Paulo. 319p.

Jacques, E.L. 2003. Flora de Grão-Mogol, Minas Gerais: Begoniaceae. Boletim de Botânica da Universidade de São Paulo 21: 107.

Kollmann, L.J.C. 2012. Diversidade, Biogeografia e Conservação das Begoniaceae do Estado do Espírito Santo, Brasil. Dissertação de Mestrado. Universidade Federal do Espírito Santo, São Mateus. 239p.

Mamede, M.C.H.; Gomes da Silva, S.J.; Jacques, E.L. \& Arenque, B.C. 2012. Begoniaceae. In: Wanderley, M.G.L.; Shepherd, G.J.; Melhem, T.S.; Giulietti, A.M. \& Martins, S.E. (eds.). Flora Fanerogâmica do Estado de São Paulo. Instituto de Botânica, São Paulo. Vol. 7, pp. 73-115.

Neale, S.; Goodall-Copestake, W. \& Kidner, C.A. 2006. The evolution of diversity in Begonia. In: Teixeira da Silva, J.A. (ed.). Floriculture, ornamental and plant biotechnology. Global Science Books, London. Pp. 106-111.

Radford, A.E.; Dickison, W.C.; Massey, J.R. \& Bell, C.R. 1974. Vascular plant systematics. Harper \& Row, Publishers Inc., New York. 891p.

Smith, L.B. \& Smith, R.C. 1971. Begoniáceas. In: Reitz, P.R. (ed.). Flora Ilustrada Catarinense. Herbário Barbosa Rodrigues, Itajaí. 128p.

Smith, L.B.; Wasshausen, D.C.; Golding, J. \& Karegeannes, C.E. 1986. Begoniaceae: Part. I: illustrated key. Part. II: annotated species list. Smithsonian Contributions to Botany, Washington. $584 \mathrm{p}$.

Souza, V.C. \& Lorenzi, H. 2012. Botânica Sistemática. Guia ilustrado para a identificação das famílias de Fanerógamas nativas e exóticas no Brasil, baseado em APG III. $3^{\text {a }}$ ed. Instituto Plantarum de Estudos da Flora LTDA, Nova Odessa. 768p.

Thiers, B. [continuously updated]. Index herbariorum: A global directory of public herbaria and associated staff. New York Botanical Garden's Virtual Herbarium. Disponível em $<$ http://sweetgum.nybg. org/science/ih/>. Acesso em 3 janeiro 2016.

Weberling, F. 1992. Morphology of flowers and inflorescences. Cambridge University Press, Cambridge. 405p.

Wilde, J.J.F.E. 2011. Begoniaceae. In: Kubitzki, K. (ed.). The families and genera of vascular plants. Flowering plants. Eudicots: Sapindales, Cucurbitales, Myrtaceae. Springer, Berlin. Pp. 56-71. 